\title{
Out in the cold: a guide to survival in community surveys
}

\author{
Geoffrey Wolff and Soumitra Pathare
}

\begin{abstract}
Liferature giving a 'behind-the-scenes' viow of community-based research is, at best, sparse. Most authors present only the finished product leaving others with the task of forever re-inventing the wheel. This paper provides a light-hearted account of the bittersweet experience of conducting a survey of community attitudes to mental lilness. The survey was part of a controlled trial of an educational campaign for neighbours of residential facillites for mentally ill people. If involved interviewing members of the local community in their own homes. The paper highlights common piffalls and gives practical advice for the novice resecarcher.
\end{abstract}

Before conducting a community survey, the novice researcher has little idea of what lies ahead. Colleagues conducting community-based research often bemoan the fact that there seems to be no literature to guide them and that published research tends to be presented as a polished fait accompli with little or no discussion of common pitfalls or practical advice for people venturing out into the field for the first time.

Having recently finished a community survey, we feel that there are practical lessons we have learnt which may well be applicable to others and we wish to share some of our experience. Our community survey was part of a controlled trial of an educational campaign around supported houses for the long-term mentally ill (Wolff et al, $1996 a, b, c, d)$. It involved interviewing the neighbours before the houses opened and again two years later.

\section{An eight point guide Selecting the sample}

Initially, we planned to identify and recruit our subjects using the electoral register. This turned out to be more difficult than we had anticipated. Many people who were on the register had already moved away and many who lived there were not on the register; one reason, perhaps, being to avoid poll tax. We therefore resigned ourselves to knocking on all the doors in our target areas to find out exactly who lived in each residence.

Lesson no 1: official figures are almost always unreliable!

\section{Timing of the survey}

This created its own set of problems. Very few people were in during working hours. This meant that most of the work had to be done after six o'clock in the evening. After a week of evenings in January spent braving the cold, the rain and the dark on the streets of Brixton, and with plenty of drenched paper and very little to show for our efforts, we were almost ready to throw in the towel; but somehow we persevered!

Lesson no 2: the bulk of the work may well have to be done in the evenings, so bewarel It is preferable to start such work in the spring; pleasant weather and longer days can make the work comparatively easy.

\section{Getting a foot in the door}

One of the most frustrating aspects of the work was people's reluctance (probably justified) to open their doors. We would see people in the house or hear the television, yet get no answer. We were later told that we had been mistaken for Jehovah's Witnesses and door-to-door salesmen and it was only after we had interviewed several people that they informed others who we were and they then opened their doors to us.

Lesson no 3: it is useful to get to know a few people in the neighbourhood and then ask them to introduce you around. It is also important to carry an identity card. People frequently ask to see it and scrutinise it well. It is therefore helpful if the photograph on the card resembles your current appearance!

\section{Safety}

Some of the residents in the neighbourhood were upset with the idea of mentally ill people in their midst and sometimes projected their anger on to us. There were occasions when we did feel threatened. In both areas, there were reports of mugging and in one area of drug dealing and a shooting.

Lesson no 4: it is advisable to go out in pairs for your own safety and this also helps to kill the time between appointments. Carry a mobile phone if possible and let someone at work know exactly where and who you are meeting that evening. 


\section{Organising your kit}

Interviewing people in their own homes is a very different experience to seeing people in your office. It is difficult, for example, to concentrate on what your subject is saying when their twoyear-old child is banging her toys on your briefcase, you have just spilled the coffee and their dog is trying to eat up your previous interview sheets! However, most people were hospitable and we were frequently offered tea, coffee, or even wine. Lesson no 5: organise yourself with a clip-board and put away all your other equipment and interview sheets in a child, dog and water resistant container!

\section{Estimating the duration of the research}

Each of the interviews lasted about an hour but for each hour spent interviewing at least three were spent trying to arrange one. With all the missed, forgotten and cancelled appointments it meant we spent over a thousand hours to get just over three hundred interviews. Data management is also very time consuming. Setting up a computer database and entering data as they are collected saves an enormous amount of time and allows problems to be ironed out at an early stage. It is easy to underestimate the time a piece of research will take and grant giving bodies are almost always reluctant to extend grants. Lesson no 6: depressive realism is an invaluable asset in estimating the total time required to complete the work.

\section{Failure to enter and attrition rate}

We managed to interview $70 \%$ of the target population. A further $20 \%$ refused and $10 \%$ could not be contacted or could not cooperate because of language differences or ill health.

At follow-up, one striking finding was that over $30 \%$ of respondents interviewed at baseline had moved away within the two years of the study. This may well influence researchers doing a longitudinal study in the choice of time between baseline and follow-up surveys. If the study can be done in one year rather than two, the attrition rate will be significantly reduced. In addition, almost $10 \%$ of respondents refused a second interview. These tended to be the people with more negative attitudes in the first instance. Just over $10 \%$ could not be contacted, defaulted from arranged interviews or were unable to cooperate because of ill health. Taken together, these, brought the re-interview rate down to about $50 \%$.

Overall, therefore, longitudinal data was available on only $35 \%$ of the original population. This clearly has implications for both the power and the generalisability of the study.

Lesson no 7: 'Oversample' at baseline to get sufficient follow-up subjects and make your follow-up period as short as possible, here again. depressive realism is an asset.

\section{Social life}

When we first started interviewing, we wasted a lot of time at weekends trying to get interviews. People did not take kindly to being wakened on a Saturday morning to be interrogated about their views on mental illness. The small window of opportunity in the afternoon before people went out for the evening also yielded poor results, as did Friday evenings. Friends, if you still have any by now, will probably spend more time talking to your answer-machine than to you.

Lesson no 8: fit all your interviewing into weekdays. It is not worth sacrificing your social life, and possibly your sanity, for such a small return at weekends.

\section{Comments}

This work was conducted in areas of London with significant levels of social deprivation and crime. There were particular problems associated with this and the surveys may well have been easier (or perhaps even more difficult) in a different setting. However, community surveys clearly do require a good deal of dedication and perseverance and they gobble up your time greedily. It is difficult at times to keep up the momentum and morale as, once started, the task may seem daunting. Indeed, the battle-cry of Alcoholics Anonymous, "one day at a time", may be usefully adopted as a community researcher's mantra although the subject matter is somewhat less addictive.

If the prospective researcher has not been put off the task yet, there are some clear rewards which are appreciated more fully in retrospect. The experience has given us valuable insights into the nature of communities in London and people's attitudes toward mental illness. This insight could not have been gained by our work in community mental health teams where we come across patients, care staff and relatives but rarely meet 'the community'.

And finally: would we do it again? Well ... hmm ... don't ask!

\section{References}

Wolff, G., Pathare, S., Craig, T., et al (1996a) Who's in the lions' den? The community's perception of community care for the mentally ill. Psychiatric Bulletin, 20, 68-71.

- . _, - . et al (1996b) Community attitudes to mentally ill people. British Joumal of Psychiatry. 168. 183-190.

- . - - - et al (1996c) Community knowledge of mental illiness and reaction to mentally ill people. British Joumal of Psychiatry, 168, 191-198. 
-, -, - et al (1996d) Public Education for Community Care: a new approach. British Journal of Psychiatry. 168, 441-447.

*Geoffrey Wolff, Clinical Scientist, MRC Social, Genetic and Developmental Psychiatry Research Centre (Social Psychiatry Section). Institute of Psychiatry, DeCrespigny Park, Denmark Hill,
London SE5 8AF. E-mail: gsw@scpu.mrc.ac.uk; Soumitra Pathare, Research Associate, Academic Department of Psychiatry, St Thomas's Hospital, UMDS

*Correspondence

\section{New from Gaskell}

\section{Safeguardsfor Young Minds}

\section{Young People and Protective Legislation}

\section{Richard White, Richard Williams, Anthony Harbour and William Bingley}

This co-publication with the NHS Health Advisory Service is concerned with aspects of the law as it applies to the welfare and protection of minors, and the management of children and adolescents in mental health services. It includes a complete update of the Concise Guide to the Children Act 1989, with a concise summary of the provisions of the Children Act. Particular issues relating to the use of the Mental Health Act 1983 with younger people and recent developments wrought by case law are also covered. Price f10.00, 84pp., 1996, ISBN $090224194 \mathrm{X}$

Available from good bookshops and from the Publications Department, Royal College of Psychiatrists, I7 Belgrave Square, London SWIX 8PG. Credit card orders can taken over the telephone (+44(0) I 7 I-235 235I, extension 146)

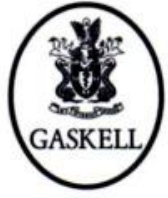

